\title{
Combining forest growth and hydrologic modelling to examine relative effects of climate and land use change: a case study in the Delegate River catchment, south- eastern Australia
}

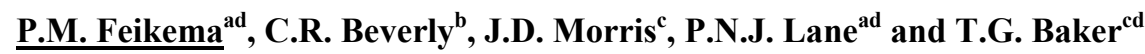 \\ ${ }^{a}$ Department of Forest and Ecosystem Science, The University of Melbourne, Parkville, Australia \\ ${ }^{b}$ Department of Primary Industries, Rutherglen, Australia \\ ${ }^{c}$ Department of Forest and Ecosystem Science, The University of Melbourne, Richmond, Australia \\ ${ }^{d}$ Cooperative Research Centre for Forestry, Hobart, Australia \\ Email:pfeikema@unimelb.edu.au
}

\begin{abstract}
Variability and changes in climate affects vegetation function and hydrological processes within the catchments. Water use of different land uses depends on factors including climate, soil, landscape position, species and management, and is closely linked with vegetation growth. There is increasing interest to predict the availability of water to downstream users, yet many modelling approaches simulating large scale climate-hydrology interactions do not explicitly take vegetation response into account. As evapotranspiration is a major component of the water balance, vegetation processes should be included when modelling climate-water relationships.
\end{abstract}

We parameterise and validate a forest growth model (3PG) that has been incorporated into the Catchment Analysis Tools (CAT) framework, to predict the effects of changes in land use and climate on the hydrology of the Delegate River catchment in south-eastern Australia. Scenarios were developed to examine relationships between changes in land use and climate, and their combined effect on evapotranspiration and streamflow.

The 1980-2000 climate record was used to generate three climate change scenarios (low, medium, high) based on projections in 2070. Three possible land use changes (current, pasture based, plantation based) were developed and used together with climate change scenarios in 21-year simulations. Although projections of climate change led to reductions in total catchment ET, there were areas within the catchment where ET was predicted to increase, even under the high climate change scenario. These areas (which accounted for between $16 \%$ and $8 \%$ of catchment area for the low and high climate scenarios respectively) were associated with native forest and plantations in areas currently limited by energy rather and water.

Predictions of changes in catchment scale ET from changes in land use from pasture to plantations are similar $(\sim 3 \%)$ to changes in ET predicted for climate change projections. However, projected reductions in rainfall are likely to have much larger effects on streamflow $(\sim 17-40 \%)$. Changes in land use led to comparatively lower effects on streamflow at the catchment scale with increases in ET and decrease in streamflow of about $20 \mathrm{~mm} / \mathrm{yr}$ (3\% and $8 \%$ respectively). These changes are similar to those in ET under medium and high climate change projections.

This study identified the importance of land use in modifying catchment response to climate change. In particular, the relative areas of forests, plantations and pasture based systems will influence the degree to which total ET and streamflow is affected, and the spatial pattern of change across the catchment. The spatial arrangement of land use may also be important at the local scale, where, for example, effects on pasturebased systems may be more pronounced if tree-based systems (with higher transpiration) are located nearby.

At local scales, an important issue is the level of interception of water by plantations, as it can affect other consumptive users and environmental flows. Considerations of scale and the unit of water management are key concepts (e.g. impact of plantations are larger at local scales than in a whole catchment). This approach helps identify those areas where effects of plantation establishment on catchment water yield may be larger under future climate change projections.

Keywords: $3 P G+, C A T$, climate change, land use change, streamflow, evapotranspiration 


\section{INTRODUCTION}

Australia's forest plantation area now exceeds 1.82 million hectares (SOFR, 2008), largely from planting softwood and hardwood species on land formerly used for agriculture in southern Australia. With higher water use by forests than pastures, and below average rainfall over the past decade in south-eastern Australia increased concerns over water security has driven the need to plan for the impact of plantation development on water resources.

Afforestation generally reduces streamflow when compared to pasture or agricultural crops (Zhang et al., 2001). Deeper roots, longer growing seasons and the ability to absorb more radiation means that trees usually use more water than pastures or agricultural crops. Knowledge of the specific effects of forestry on streamflow in Australia is based on several paired catchment treatment experiments (e.g. Webb and Kathuria, 2011) and are site specific in terms of local climate, geomorphic and hydrogeological conditions.

The need to scale up localised research results to larger catchments has led to the development of models to assist water resource managers. The majority of studies that simulate the effect of changes in land use on streamflow in forested catchments have not considered the function of forests as influenced by spatial distribution (Lorz et al., 2007). Factors that vary over space including landscape attributes such as elevation, aspect, slope and soil depth all influence the growth and water use of forests.

Studies that do include the spatial location of forests invariably involve empirical approaches to simulating forest development and transpiration (e.g. Watson et al., 1999; Lane et al., 2010). Plantation growth and transpiration depends on the climate factors, the amount and seasonal distribution of rainfall, the hydrological factors affecting supply and the response of trees to climate, hydrology and plantation management. We argue that more emphasis should be placed on understanding the function of vegetation and how landscapes will respond by investigating and linking the dominant processes from plot to catchment scales.

An important point is to provide sufficient detail in integrated models to adequately describe the spatial forest-related processes that influence streamflow. More importantly, the questions being asked in relation to the effects of climate change mean that many processes not previously considered now need to be included to take into account important influences and interactions. In water limited environments, for example, a reduction in rainfall may lead to a reduction in leaf area index, which will modify the rainfall-runoff relationship. More broadly, the effects of forests to modify the water and carbon balance are related to their landscape position.

We first validate a forest growth model (3PG; Landsberg and Waring, 1997) that has been integrated into a catchment modeling framework (CAT; Beverly et al. 2005) and described by Feikema et al. (2010), against observed catchment streamflow for the Delegate River catchment, south-eastern Australia. The model was then used to examine the relative effects of changes in conversion between pasture and plantations, and projections in climate change on forest evapotranspiration and catchment streamflow.

\section{THE DELEGATE RIVER CATCHMENT}

The Delegate River catchment (Delegate River at Quidong; $\left.36.91^{\circ} \mathrm{S}, 149.03^{\circ} \mathrm{E}\right)$ straddles the Victorian and New South Wales border in south-eastern Australia (Figure 1). Water from the catchment flows into the Snowy River. Elevation within the catchment ranges from 620 to $1300 \mathrm{~m}$ ASL (Figure 2a) and long term mean rainfall (1975-2005) varies from approximately 590 to $1660 \mathrm{~mm} / \mathrm{yr}$. The majority of the catchment is covered by native vegetation $(46 \%)$ and pasture $(38 \%)$ with a smaller proportion of plantations of $P$. radiata $(15 \%)$ (Figure $2 c)$.

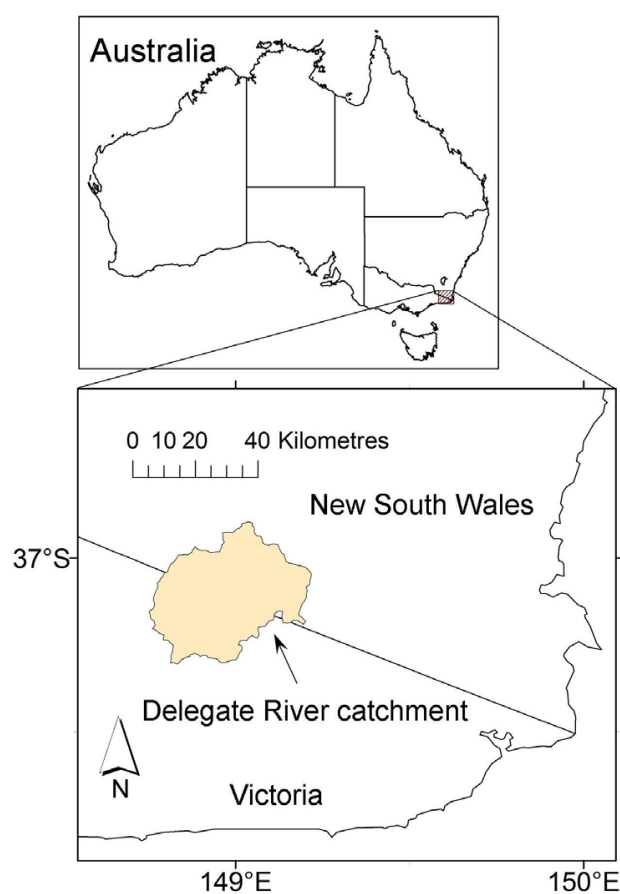

Figure 1. Location of the Delegate River catchment. 


\section{DATA}

\subsection{Climate}

Mean annual climate surfaces between 1975-2005 (Figure 2b) were generated using ANUClim (Hutchinson, 1999) that combine the DEM and temporal climatic data to generate a smoothed climate surface. Daily climate data was obtained for climate stations in the Patched Point Data (PPD) network sourced from Queensland Department of Natural Resources and Environment's SILO service. A Voronoi diagram mapped the nearest PPD climate station for each point in the catchment. The PPD combine original Bureau of Meteorology measurements for a given climate station with a process for infilling any gaps in the record using interpolation methods discussed in Jeffrey et al. (2001). Time series data for rainfall, radiation, temperature and evaporation were scaled for each point in the catchment using the ANUClim climate surfaces.

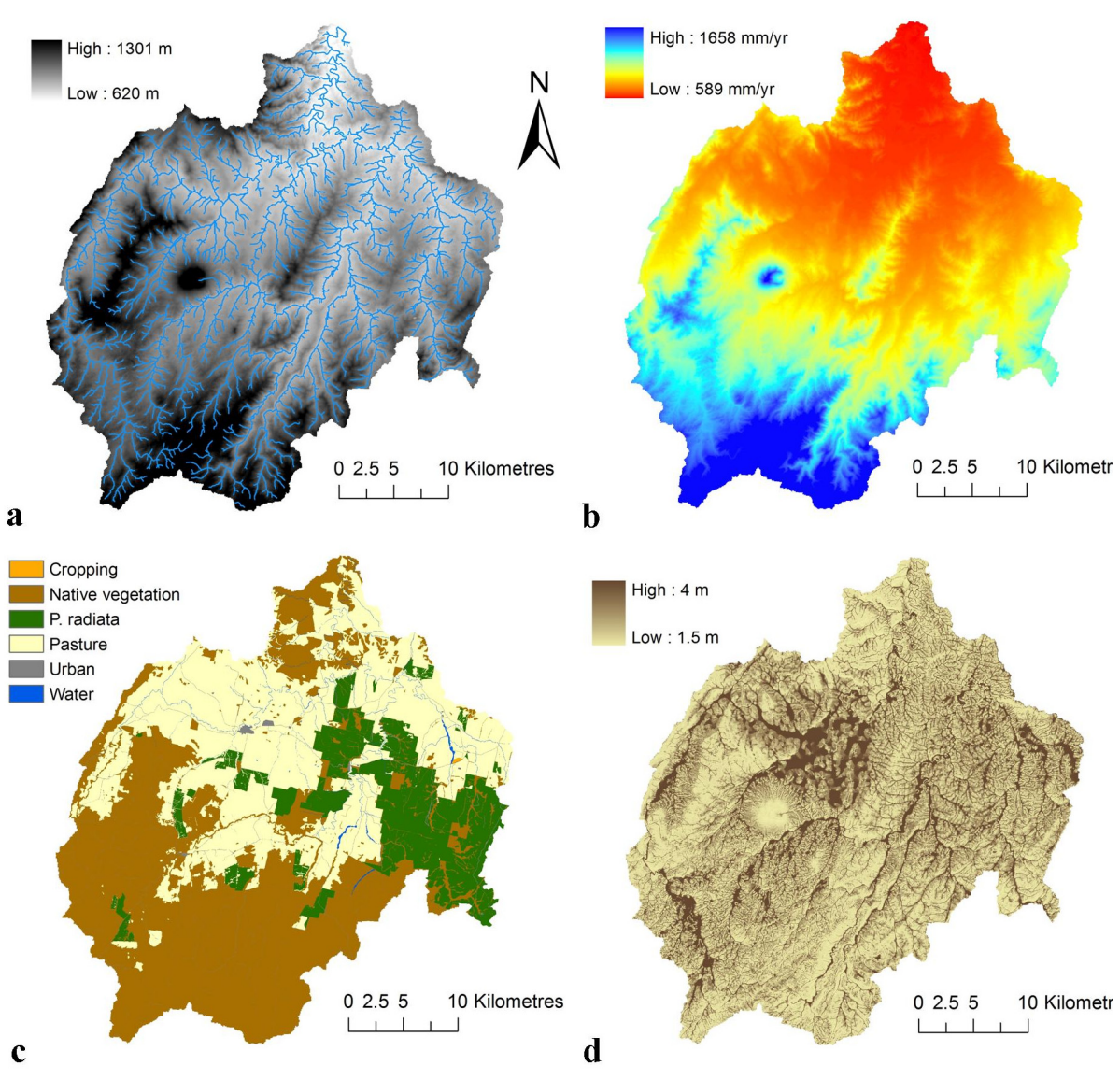

Figure 2a) Digital elevation model with steam network, b) Long term mean rainfall (1975-2005), c) Current land use, and d) Estimated soil depth.

\subsection{Land use}

Spatial data for land use (Figure 2c) was derived from the Australian Land Use Mapping (ALUM) classification (BRS, 2001). More detailed spatial data on plantation species and year of planting kindly provided Willmott Forests Pty Ltd and Forests New South Wales. Plantation data was subsequently incorporated into the ALUM land use data and is shown in green in Figure 2c. The year of plantation establishment during the simulation period was provided as a spatial layer. Annual pasture was assumed to exist prior to plantation establishment.

Growth and development of plantations was simulated using the 3PG+ forest growth model described by Feikema et al. (2010). Water use for other land uses, including native forest, crops and pastures, was estimated using a crop factor model where transpiration is calculated from the distribution of green cover and a crop factor, and is sensitive to rooting depth and available soil water (Doorenbos and Pruitt, 1977). 
Feikema et al., Combining forest growth and hydrologic modelling to investigate catchment hydrology

\subsection{Soil}

Soil type data was obtained from a 1:250,000 statewide soil attribute coverage (Rab et al., 2002). Spatial information on soil depth is generally not available, and used the MrVBF index (multi-resolution valley bottom flatness) described by Gallant and Dowling (2003) to identify valley bottoms by combining flatness (inverse of slope) with lowness (relative to a circular surrounding area) at a range of scales. We applied the version of MrVBF used in 2CSalt (Stenson, et al., 2011) This technique assumes that i) valley bottoms are low and flat relative to their surroundings, ii) valley bottoms occur at a range of scales, and iii) large valley bottoms are flatter than smaller ones. Index values were then rescaled so that hilltops had relatively shallow soil $(1.5 \mathrm{~m})$ and valley bottoms had relatively deeper soil $(4 \mathrm{~m})$ to agree with data from soil profile morphology at one location within the catchment (see Feikema et al., 2010) and summed median thickness of the A and B horizons from McKenzie et al. (2000). Resulting estimates of soil depth across the catchment are shown in Figure 2d.

\subsection{Validation}

Simulated monthly streamflow were compared with measured streamflow between 1980 and 2000 to evaluate model performance using criteria including the Nash and Sutcliffe (1970) coefficient of model efficiency $(E)$ and differences in means expressed as a percentage.

\subsection{Scenarios}

To facilitate comparison between potential effects of changes in climate and land use on catchment hydrology, several scenarios were developed in land use i) remained the same, where all area currently under pasture and plantations was converted to ii) pasture, or to iii) P. radiata plantations, with i) no ii) low iii) medium and iv) high climate change projections. Simulations for each scenario were used the same 21 year climate sequence from 1980 to 2000 to provide a range of relatively wet and dry years. We compare changes in hydrologic outputs over the same time period for the different scenarios. This assumes that hydrologic response is reflected immediately after land use change.

We used three climate change projections (low, mid and high) based on the B2, A2 and A1F1 scenarios of the IPCC (SRES, 2000) generated using CSIRO's global atmosphere model (CCAM) simulation is driven by CSIRO's Mark2 climate model (Hennessy et al., 2006). Regional climate change patterns were used to scale rainfall, minimum temperature, maximum temperature and solar radiation.

We determined the potential impact of climate change at a single point in time (in the year 2070). In this method, atmospheric concentration of carbon dioxide $\left(\left[\mathrm{CO}_{2}\right]\right)$, temperature, radiation and rain pattern of change impacts were adjusted in the 1980-2000 weather sequence to represent projections in 2070. This enables a comparison of the daily climate change scenario data with the baseline historical data. The method allows prediction of the distribution of biophysical response over a range of years and the departure from the historical annual rainfall and mean daily temperature climate pattern under the 2070 climate projections. A step change was used rather than a gradual change in projected climate, so as to avoid interaction of climate with forest age, and to facilitate a more direct comparison between land use and climate scenarios with the same climate sequence.

Previous studies have suggested that $\left[\mathrm{CO}_{2}\right]$ may have a relatively small yet significant effect on catchment hydrology (McCallum et al., 2010). Experimental and theoretical research suggests that light saturated assimilation rate and light use efficiency of vegetation increase as $\left[\mathrm{CO}_{2}\right]$ increases leading to increases leaf area, which may result in an increase in transpiration (Ainsworth \& Rogers, 2007). Research also suggests that maximum stomatal conductance decreases with increasing $\left[\mathrm{CO}_{2}\right]$, resulting in a reduction in transpiration (Ainsworth \& Rogers, 2007). We include the effects of changes in $\left[\mathrm{CO}_{2}\right]$ on plant function as described by Almeida et al. (2009) by introducing two additional modifiers that affect canopy quantum efficiency and canopy (stomatal) conductance.

\section{RESULTS AND DISCUSSION}

\subsection{Calibration}

The resulting calibration yielded a good fit of predicted to observed data (Figure 3). The value of $E$ was 0.79 , indicative of an good model fit, and the difference in the mean and standard deviation between predicted and observed monthly flow was $+4.8 \%$ and $-7.6 \%$ respectively. 


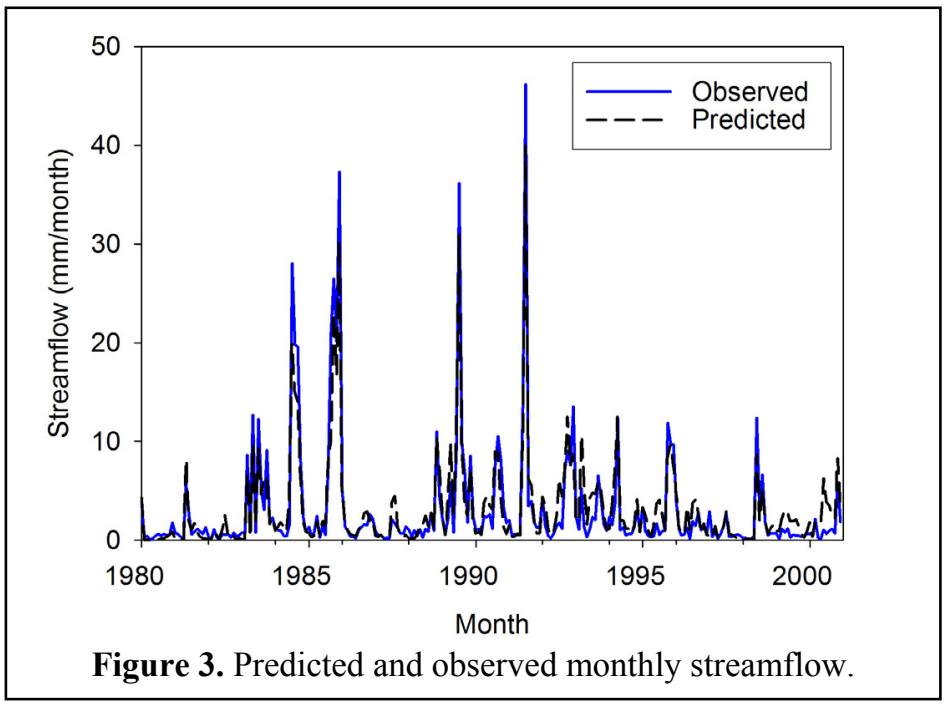

\subsection{Climate change projections}

Differences in transpiration for the 21 year simulation across the catchment relative to the no climate change scenario are shown in Figure 4. Transpiration is an integrator between energy demand, leaf area index and water supply. Increases in transpiration are indicative of relatively favourable balances between these, whereas reductions in transpiration may associated with a combination of reduction in water supply, reduction in LAI, and/or high vapour pressure deficits that induce stomatal closure to limit water loss.

A summary of ET and streamflow for all scenarios is given in Table 1. In all scenarios there were areas where transpiration increased with climate change. These were generally plantations and native forest in the higher rainfall zones. For the low climate change scenario, areas in which transpiration increased accounted for $16 \%$ of the catchment area. This figure for the medium and high climate change scenarios was $13 \%$ and $8 \%$ respectively.

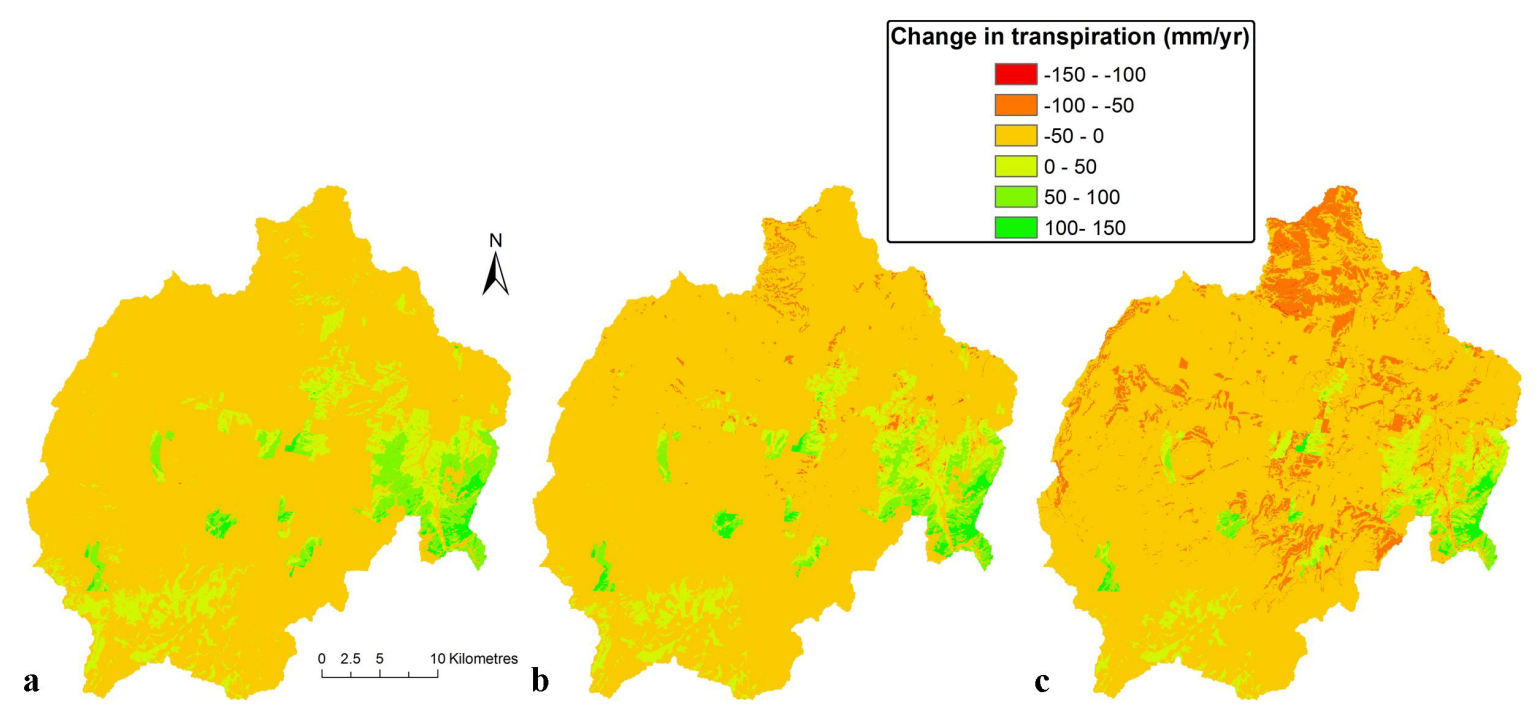

Figure 4. Change in transpiration relative to no climate change for a) low, b) medium, and c) high climate change projections with current land use. 
Feikema et al., Combining forest growth and hydrologic modelling to investigate catchment hydrology

\subsection{Change in land use}

Changes in land use when compared to climate change projections led to lower effects on streamflow at the catchment scale (Table 1) with increases in ET and decrease in streamflow of about $20 \mathrm{~mm} / \mathrm{yr}$ ( $3 \%$ and $8 \%$ respectively). These changes are similar to those in ET under medium and high climate change projections.

\subsection{Combined changes in land use and climate}

While effects on ET from changes in land use from pasture of plantations are similar ( 3\%) to those predicted for climate change projections, projected reductions in rainfall are likely to have larger effects on streamflow ( 17-40\%) (Table 1). Although overall catchment ET is predicted to decrease under all climate change projections, certain parts of the catchment, particularly where energy (rather than water) is limiting, will experience higher rates of ET. These areas tend to be tree based systems. For the Delegate River catchment, simulations suggest that increasing proportions of trees relative to pasture may result in larger reductions in streamflow because ET of tree based systems will be higher under climate change scenarios.

Table 1. Summary of changes in average ET and streamflow $(\mathrm{mm} / \mathrm{yr})$ from simulations of change in land use and climate. Percentage difference from no climate change scenario given in brackets. Note that in all scenarios, the proportion of the catchment covered by native forest remains at $47 \%$.

\begin{tabular}{lcccc}
\hline \multicolumn{2}{l}{ Land use scenario } & $\begin{array}{l}\text { Current } \\
\text { 38\% pasture }\end{array}$ & \begin{tabular}{l} 
Pasture based \\
53\% pasture \\
\multicolumn{2}{l}{ Climate scenario }
\end{tabular} & $\begin{array}{l}\text { Plantation based } \\
\text { 0\% pasture }\end{array}$ \\
\hline \multirow{2}{*}{ No change } & ET & 6 P. radiata & 0\% P. radiata & 53\% P. radiata \\
& Q & 254 & 656 & 687 \\
\hline \multirow{2}{*}{ Low } & ET & $-4(-0.6 \%)$ & $-14(-2.2 \%)$ & $+11(+1.6 \%)$ \\
& Q & $-45(-17 \%)$ & $-34(-13 \%)$ & $-60(-26 \%)$ \\
\multirow{2}{*}{ Medium } & ET & $-13(-1.9 \%)$ & $-24(-3.7 \%)$ & $+4(+0.6 \%)$ \\
\multirow{2}{*}{ High } & Q & $-71(-28 \%)$ & $-60(22 \%)$ & $-88(-38 \%)$ \\
& ET & $-30(-4.6 \%)$ & $-41(-6.2 \%)$ & $-17(-2.5 \%)$ \\
& Q & $-105(-42 \%)$ & $-95(-36 \%)$ & $-119(-51 \%)$ \\
\hline
\end{tabular}

\section{CONCLUSIONS}

This study identified the importance of land use in modifying catchment response to climate change. In particular, the relative areas of forests, plantations and pasture based systems will influence the degree to which total ET and stream flow is affected, and the spatial pattern of change across the catchment. The spatial arrangement of land use may also be important at the local scale, where, for example, effects on pasture-based systems may be more pronounced if tree-based systems (with higher transpiration) are located nearby. At local scales, an important issue is the level of interception of water by plantations as it affects other consumptive users or environmental flows. Considerations of scale and the unit of water management are important concepts. This approach helps identify those areas within catchments where effects of plantations on hydrology may be larger under future climate change projections. It also provides a mechanism for assisting management of catchments to adapt to climate change.

\section{ACKNOWLEDGMENTS}

The work was supported by Forest and Wood Products Australia (FWPA), the Victorian Department of Primary Industries, and the Victorian Department of Sustainability and Environment. Sam Ebert and Craig Hamilton (DSE, Wodonga) provided GIS support for the CAT catchment modelling. Spatial plantation data for Pinus radiata was provided by Arjan Wilkie (Willmott Forests) and by Tim Cashman, Charlie Farrugia and Ashley Webb (Forests New South Wales).

\section{REFERENCES}

Ainsworth, E. and Rogers, A. (2007). The response of photosynthesis and stomatal conductance to rising $\left[\mathrm{CO}_{2}\right]$ : mechanisms and environmental interactions. Plant, Cell and Environment, 30, 258-270. 
Feikema et al., Combining forest growth and hydrologic modelling to investigate catchment hydrology

Almeida, A.C., Sands, P.J. Bruce, J., Siggins, A.W. Leriche, A. Battaglia, M. and Batista, T.R. (2009). Use of a spatial process-based model to quantify forest plantation productivity and transpiration efficiency under climate change scenarios. In Anderssen, R.S., R.D. Braddock and L.T.H. Newham (eds) 18th World IMACS Congress and MODSIM09 International Congress on Modelling and Simulation. Modelling and Simulation Society of Australia and New Zealand and International Association for Mathematics and Computers in Simulation, Cairns, Australia. 13-17 July 2009, pp. 1816-1822. ISBN: 978-0-9758400-7-8.

Beverly, C., Bari, M., Christy, B., Hocking, M. and Smettem, K. 2005. Predicted salinity impacts from land use change: comparison between rapid assessment approaches and a detailed modelling framework, Australian Journal of Experimental Agriculture, 45, 1453-1469.

BRS (2001). Land use mapping at catchment scale. Principles, procedures and definitions. Department of Agriculture Fisheries and Forestry and Bureau of Rural Science, Canberra, ACT.

Doorenbos, J. and Pruitt, W.O. (1977). Guidelines for predicting crop water requirements. FAO Irrigation and Drainage Paper. No 24 FAO, Rome.

Feikema, P.M., Morris, J.D., Beverly, C.R., Collopy, J.J., Baker, T.G. and Lane, P.N.J. (2010). Validation of plantation transpiration in south-eastern Australia estimated using the $3 \mathrm{PG}+$ forest growth model. Forest Ecology and Management, 260, 663-678.

Gallant, J.C. and Dowling, T.I. (2003). A multiresolution index of valley bottom flatness for mapping depositional areas, Water Resources Research, 39, 1347, doi:10.1029/2002WR001426.

Hennessy, K., Page, C., Durack, P. and Bathols, J. (2006). Climate Change Projections for Victoria. CSIRO Marine and Atmospheric Research, Aspendale, Victoria.

Hutchinson, M.F., Nix, H.A., Houlder, D.J., and McMahon, J.P. (1999). ANUCLIM Version 1.8 User guide. In. Centre for Resource and Environmental Studies, The Australian National University.

Jeffrey, S.J., Carter, J.O., Moodie, K.B. and Beswick, A.R. (2001). Using spatial interpolation to construct a comprehensive archive of Australian climate data. Environmental Modelling and Software, 16, 309-330.

Landsberg, J.J. and Waring, R.H. (1997). A generalised model of forest productivity using simplified concepts of radiation-use efficiency, carbon balance and partitioning. Forest Ecology and Management, 95: 209-228.

Lane, P.N.J., Feikema, P.M., Sherwin, C.B., Peel, M.C. and Freebairn, A.C. (2010). Modelling the long term water yield impact of wildfire and other forest disturbance in Eucalypt forests. Environmental Modelling and Software, 25, 467-478.

Lorz, C., Volk, M. and Schmidt, G. (2007). Considering spatial distribution and functionality of forests in a modeling framework for river basin management. Forest Ecology and Management, 248, 17-25.

McCallum, J.L., Crosbie, R.S., Walker, G.R. and Dawes, W.R., 2010. Impacts of climate change on groundwater in Australia: a sensitivity analysis of recharge. Hydrogeology Journal, 18, 1625-1638.

McKenzie, N., Jacquier, D.W., Ashton, L.J. and Cresswell, H.P. (2000). Estimation of soil properties using the Atlas of Australian soils. In. CSIRO Land and Water, Canberra, ACT, p. 12.

Nash, J.E. and Sutcliffe, J.V. (1970). River flow forecasting through conceptual models part I - A discussion of principles. Journal of Hydrology, 10, 282-290.

O’Leary G. and Christy, B. (2009). Generating future climate scenarios for Victoria, Department of Primary Industries, Victoria. 7pp.

Rab, A., Smith, C., and Rees, D. (2002). The 1:250000 Statewide Soil Attribute Coverage Documentation. Department of Natural Resources and Environment, Government of Victoria, Centre for Land Protection Research, Epsom, Victoria.

SOFR (2008) Australia's State of the Forests Report 2008. www.daff.gov.au/forestsaustralia

SRES (2000). Special Report on Emission Scenarios: Summary for Policymakers. A Special Report of Working Group III of the Intergovernmental Panel on Climate Change. Cambridge University Press, Cambridge, UK, 27 pp.

Stenson, M.P., Littleboy, M. and Gilfedder, M. (2011). Estimation of water and salt generation from unregulated upland catchments. Environmental Modelling and Software, 26, 1268-1278.

Watson, F.G.R., Vertessy, R.A and Grayson, R.B. (1999). Large-scale modelling of forest hydrological processes and their long-term effect on water yield. Hydrological Processes, 13, 689-700.

Webb, A.A. and Kathuria, A. (2011). Response of streamflow to afforestation and thinning at Red Hill, Murray Darling Basin, Australia. Journal of Hydrology, In Press.

Zhang, L., Dawes, W.R. and Walker, G.R. (2001). Response of mean annual evapotranspiration to vegetation changes at catchment scale. Water Resources Research, 37, 701-708. 